\title{
ENTREVISTA A LUIS BEDOYA REYES
}

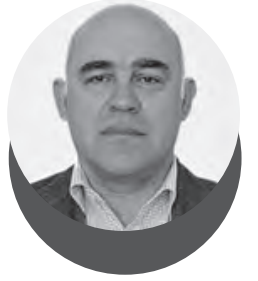

\author{
Lizardo A. Seiner \\ ORCID: 0000-0001-5783-7088 \\ Profesor de Globalización: \\ Apertura y Tendencias \\ Área Académica de Administración \\ Facultad de Negocios, UPC Lima - Perú \\ pchulsei@upc.edu.pe
}

Cómo citar esta entrevista:

Seiner, L.A. (2018). Entrevista a Luis Bedoya Reyes,

Luis Bedoya Reyes, gran orador y político experimentado, genera una importante repercusión en la vida política del Perú. En esta entrevista, más que enfocarse en los elementos coyunturales de la politica actual, está centrada en las experiencias de vida, que sólo un hombre centenario como Luis Bedoya Reyes puede compartir. Las reflexiones se expresan sobre la dignidad humana, la cooperación entre los politicos, y la libertad, para alcanzar mayores niveles de productividad y desarrollo para el Peru.

Palabras clave: Politica, desarrollo económico, libertad.

Luis Bedoya Reyes, great experienced and speaker politician, generates an important repercussion in the Peruvian political life. In this interview, rather than focus on conjunctural aspects of current politics, is oriented on his life experiences, that only a man like Luis Bedoya Reyes can share. Reflections are expressed about human dignity, cooperation between politicians, and freedom, as factors to achieve more development and productivity for Peru.

Keywords: Politics, economic development, freedom.

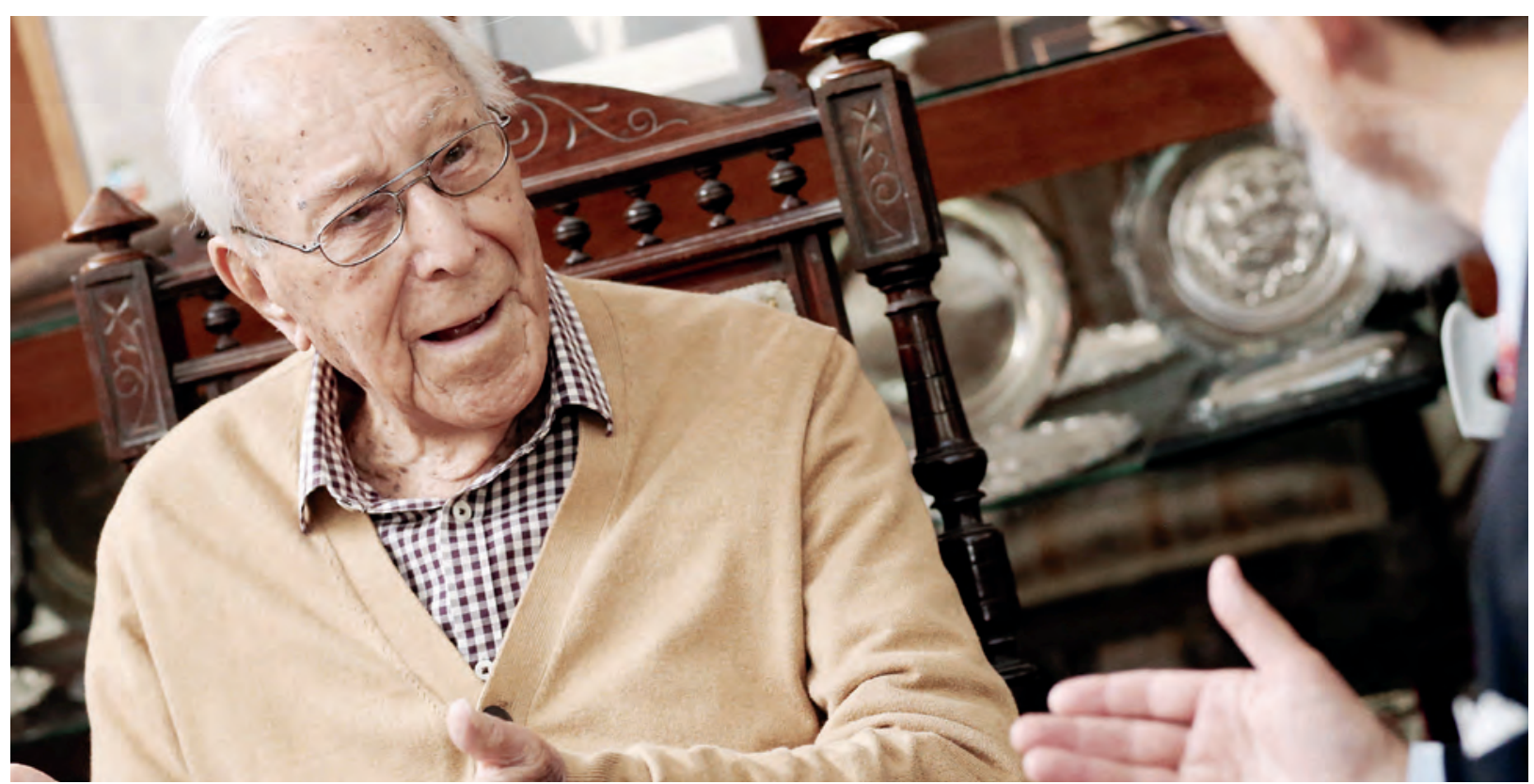

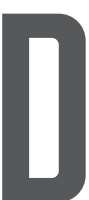

r. Bedoya, muchas gracias. Estoy muy honrado por la ocasión; por lo que usted significa en la vida del país. Una persona que es capaz de ver un siglo del modo tan lúcido con que recuerda las cosas en su reciente libro de memorias, Joven Centenario: Realidades de una Vida (2018) es impresionante. Es un recorrido por el Perú del siglo XX y esa es básicamente la razón por la que agradezco su deferencia en otorgarme esta entrevista.
Dr. Bedoya, esta es una entrevista distendida, no está guiada por la premura de la política ni por la coyuntura, sino por la lectura de las experiencias que marcan su vida, especialmente las relacionadas con los valores, la universidad y la dimensión ideológica de la política. Para la primera pregunta, la que estuve pensando por días, evoqué la entrevista que usted brindó hace muchos años a César Hildebrandt. En ella, afirma que en el Perú no se podía hacer política a 
partir del "anti". Lo decía usted en relación con lo que había significado la dura coyuntura de la Asamblea Constituyente, saliendo del régimen militar. Pensé que esa reflexión profunda que usted hizo sobre el "anti" es aplicable para estos tiempos; no se puede hacer política probablemente en el Perú ni en ningún lugar a partir del "anti", sino a partir del diálogo, ámbito en el cual usted siempre dio testimonio de apertura y de concesión.

Para eso tenía yo una cierta experiencia, no calculada ni presente en mi pensamiento pero evidentemente vigente. Me sitúa en la época en la que se trataba de entrar a la universidad; y discúlpeme si hago el relato: yo venía con la gloria de ser el número uno--está en el libro. Incluso con una anécdota muy curiosa que también está en el libro, con respecto a la enseñanza de mi madre de las primeras letras, ya que tres hermanos, una mujer y dos varones, estábamos desde el segundo de primaria en el mismo año y llegamos al quinto de media juntos. Me trasladaron al colegio Guadalupe, que es el primer colegio nacional, para cursar cuarto y quinto de secundaria. Yo venía de un colegio muy pequeño en Miraflores, que había sido mantenido por grandes maestros, que venían de enseñar en la Escuela Normal, y que fueron educados en Estados Unidos. En este colegio, mi hermano Augusto, que me seguía, y yo, nos sacábamos todos los premios porque éramos no más de veinte alumnos por clase y estábamos los dos en la misma clase. Fuimos los dos a Guadalupe y en Guadalupe un profesor que después encontraría yo en la universidad, Sánchez Palacios, muy buen abogado y buen maestro, estaba introduciendo precisamente una metodología distinta. Su metodología no era dictar profesionalmente la lección, sino adelantar de qué tema nos iba a tratar en la lección siguiente, con el fin de que nos preparásemos en el tema para conversarlo en clase; porque la conversación sobre ese tema iba a ser con dos o tres alumnos seleccionados en ese momento. Esto obligaba a que todos tuviésemos que leer y prepararnos antes de la clase porque íbamos a dar un examen oral ante toda la clase con nuestro maestro que había señalado el tema. Interesante de por sí porque él enseñaba Historia Contemporánea, que era un elemento común en la inquietud de los muchachos.

\section{Estamos hablando de mediados de los años ' 30 .}

Estamos hablando exactamente de los años ‘34 y '35. A

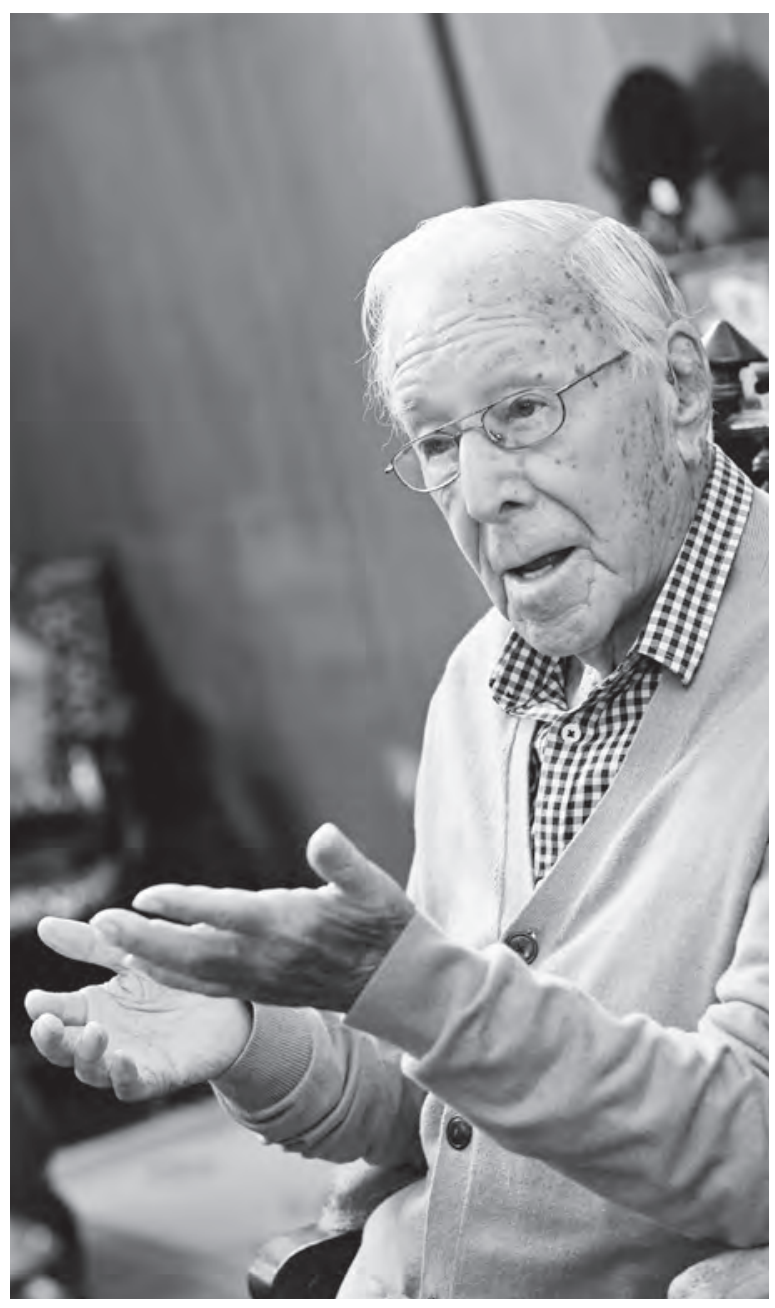

mí me había apasionado mucho la Historia y había leído bastante sobre ella. Quizás me excedía en mi pretensión de saber y soy muy desinhibido; no hay personalidad que me haya impresionado. He tenido mucha suerte, en conocer a Don José Luis [Bustamante y Rivero]. Me llamó el profesor casi al final del año a examen y yo era nuevo en la clase porque había entrado en cuarto de media, mientras que mis compañeros venían desde primero. Yo era una incógnita para los demás, fuera de la amistad que se había trabado en el deporte. Yo practicaba fútbol como básquet de manera que por ahí estaba colado como un deportista más. Y el día que me tocó el examen comencé a conversar con el maestro; mi clase se impresionó, pero el maestro se impresionó más. Me tocó dos oportunidades más con este maestro. 
En tercero de Derecho, Sánchez Palacios fue mi profesor de Derecho Procesal Civil; una autoridad en la materia y seguía con su misma metodología: señalaba el tema de la próxima clase y seleccionaba a los alumnos para conversar con ellos y, según eso, calificarlos.

\section{No era la figura del profesor magíster dixit.}

Así es, éste no lo practicó. Éste fue de interrogante permanente. Pero yo atropellaba en mi dicción y no le dejaba que me preguntara. Cada vez que preguntaba venía mi disertación. Se quedó impresionado. Yo saqué en Guadalupe la medalla de oro, que era el único premio en la promoción que salía. Y en cada promoción salíamos más de 200 porque éramos 50 en cada clase y eran entre 5 y 6 secciones cada año. El profesor me volvió a encontrar en tercero de Derecho. Yo sabía qué temas iba a tratar pero estaba con la mente muy tomada: había conocido a quien sería después mi señora y estaba en todas.

\section{En el entusiasmo.}

La novedad de uno. Tercero de Derecho quiere decir que tenía ya cinco años en la universidad; tres de derecho y dos de letras. Llegué tarde a la clase, noté que me preguntó y me dije "te fregaste Bedoya"; yo no había abierto nada, no tenía tiempo porque estaba preocupado por otras cosas. “Bedoya Reyes Luis, en la luna por supuesto”. Me dijo: “¿Qué le ha pasado? ¿No es usted un joven a quien yo he conocido en el colegio Guadalupe?” "Sí doctor". "¿Y qué le ha pasado hijo?" "Doctor, estoy enamorado y me ha cogido usted en un día que no he tenido tiempo para leer".

\section{Ahora, cuando a usted luego le tocó ser profesor ¿cuál fue la metodología de Luis Bedoya en la docencia? ¿Aplicó la misma metodología de Sánchez Palacios?}

No, porque solamente enseñé Castellano, que no se presta para eso. Además, sólo fui profesor esporádicamente. Nunca he tenido cátedra en Derecho.

\section{Paradójico.}

Ni siquiera profesorado en Guadalupe. Nací abogado, nada más que abogado. Pero lo curioso es que tuve con Sánchez Palacios una tercera etapa. Cuando postulé a la Alcaldía de Lima, la confrontación era entre la renovación y la permanencia. Los que habían sido los seguidores de Odría estaban con Odría en el poder, en ese momento, proceso electoral. El APRA escogió como candidata a la esposa de Odría.

\section{Doña María Delgado.}

Mujer muy meritoria por su humildad; su voluntad de servicio; y su tono siempre modesto, humilde, pero eficiente y razonable. Ese tipo de contrincante con el cual uno no tiene por donde golpear. Mujer en primer lugar, ni con el pétalo de una rosa.

Y Sánchez Palacios estaba de concejal en el grupo porque en la lista que Odría ofreció y respaldó el APRA había gente de mucha calidad. Estaba presente ya Belaúnde y yo había dejado de ser Ministro de Justicia, cargo que ocupé tres veces. Belaúnde me pidió que postulara, una operación muy larga de contar. Para mí fue una frustración porque

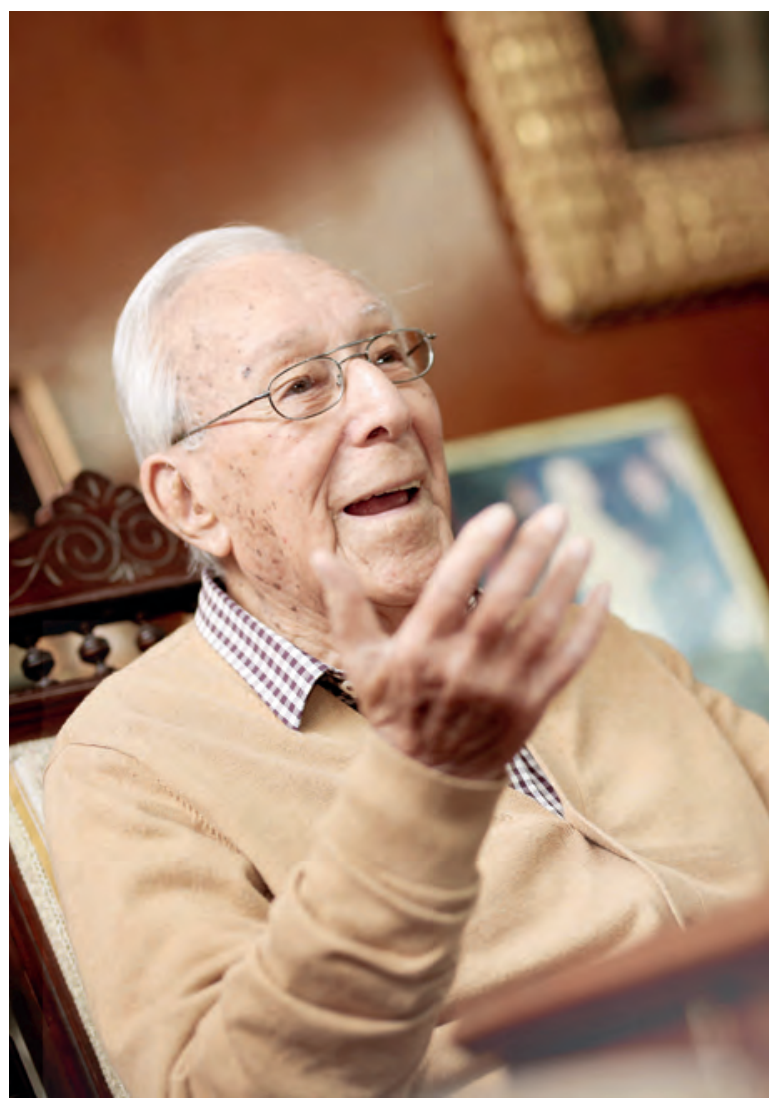


estaba muy contento como Ministro de Justicia y Belaúnde me confesó: "Mire Bedoya, el 15 de noviembre son las elecciones y el 16 lo estoy llamando para que vuelva a juramentar". Daba por hecho que iba a ser derrotado. El APRA y Odría sumaban más votos de los que teníamos Belaunde con la Democracia Cristiana.

\section{Era la coalición APRA-UNO contra AP-DC.}

Pero juntados después de haber hecho cada uno su lista y haber concurrido independientemente. Juntados después de haber ganado los dos muy buena votación, pero yo los había derrotado a los dos por separado. Habían confiado plenamente en que su sola presencia iba a originar una sumatoria de votos. Belaúnde me dijo: "Mire, yo no le pido que gane, no, eso no es posible, hay mucha desproporción. Yo lo único que le pido es que obtenga el máximo posible de votos, siendo muy buen candidato. Va a ser usted un muy buen candidato". Le pregunté por qué y me respondió: "Porque me bastará que sume más votos que los que saqué en las elecciones presidenciales hace tres meses y no un desastre tremendo, con una derrota desproporcionada, tres meses después de haber triunfado".

Gané. Lo que no perdonaron Haya ni Odría. Pero sobre todo Haya, quien tuvo que sepultar el famoso lema del APRA: "SEASAP".

\section{“Sólo el aprismo...}

...salvará al Perú". Ni junto al Odriísmo, el APRA pudo derrotarnos en Lima y Callao.

\section{Y usted se sentía limeño y chalaco ciertamente.}

Lógico. Yo estaba en Lima, pero lo que hizo, con alguna explicación Belaúnde fue que clausuráramos la campaña en el Callao.

\section{A lo cual usted se opuso.}

No, yo no tuve inconveniente, dado que prácticamente la mitad del Callao votaba en Lima. Gané. Vino la juramentación. Eso es a lo que quería referirme con respecto a Sánchez Palacios. Sánchez Palacios era concejal de la Unión Nacional Odriísta. Yo, su viejo alumno de Guadalupe.

Que luego encontró en San Marcos.
Emplazado en San Marcos. Además, estaban el rector de La Molina ${ }^{1}$ y hacendados del norte del país, como también gente muy importante y grandes juristas. También gente nueva, como Valle Riestra en la juventud y hombres valiosos, como Manuel Aguirre Roca, que fue el primer Presidente del Tribunal Constitucional. Todos ellos estaban en la oposición. Y para tomarles el juramento, porque me tocaba tomar el juramento a cada uno, de un lado y de otro, el secretario lee: "Manuel Sánchez Palacios". No sé cómo me conmocionó. Vi a mi maestro, quien se levantaba para venir hasta el estrado a juramentar, y automáticamente y sin pensarlo me paré. “Le pido perdón Presidente y su autorización, voy a apartarme unos minutos, voy a alcanzar a mi maestro”. “Doctor Sánchez Palacios, por favor espéreme que voy a ir por usted".

\section{Qué lindo gesto.}

Puse la situación a mi favor. Y por eso su gente, la del Apra y la del Odriísmo, me respetó mucho durante mis seis años de alcalde. Porque gané en el segundo periodo.

\section{Era un gesto de entereza, de moralidad y de reconocimiento al maestro.}

El hombre se impresionó a tal grado que con las justas podía caminar. Hasta que íbamos juntos al estrado, sin necesidad de llegar a la mesa le tomé el juramento. Le dije que por favor salude al Presidente porque estábamos al otro lado de la mesa.

En su libro, Dr. Bedoya, hay una parte final que me llamó mucho la atención cuando usted señala en líneas generales, cuál es su vocación, su afición, su deber y su encargo. Cuando usted hace alusión a la vocación, dice el Derecho. Cuando hace alusión a la afición, menciona a la Historia. El deber indudablemente usted lo enfoca en la Familia y cuando señala el encargo, usted se refiere a la Política. Son cuatro elementos centrales de su vida y jerarquizados que sintetizan el pensamiento o las líneas directrices de una vida digna.

Es una confirmación final de lo que la vida ha sido. Yo no me propuse eso cuando tenía 25 ó 30 años. Yo encontré esas directivas cuando tenía ya 60 años; entonces me di cuenta que había estado cumpliendo eso. Por ejemplo, en el caso de la familia hice lo mismo que hizo mi padre. Mi padre comenzó muy modestamente su trabajo; llegó 
prácticamente a la gerencia de la empresa en la que trabajaba. Nunca descuidó la familia: era una cosa elevar el estándar de vida pero el núcleo de la familia iba con él. En la política, para mí, en las ideas y el estilo, León Barandiarán había sido el hombre que más me impresionó en la Facultad de Derecho. Eminencia, joven pero desordenado: su maletín hablaba de sus años por la vejez que mostraba. Y cuando le pedimos que enseñara un curso muy difícil, porque ningún catedrático quería tomarlo, que era Derecho Internacional Privado. Este curso aborda la competencia de los derechos de país a país en problemas que puedan surgir, por ejemplo, una persona peruana que radica en Francia y que en un viaje que hace a Italia le ocurre un accidente del cual es responsable, o ha comprado una propiedad y se está discutiendo la propiedad. ¿Qué ley aplicas? León Barandiarán lo tomó con una condición: "soy alumno como ustedes"; y lo fue. Cuando le plantearon un caso dijo: "ahora no les puedo contestar porque tengo que revisarlo". Y cuando lo revisó tres semanas después, nos dio la respuesta en una clase magistral. Parecíamos el tribunal escuchando su informe.

Gente como ese hombre me ha señalado la vida. Como don José Luis Bustamante y Rivero. Yo no lo conocía durante el tiempo que hizo su campaña. Pero yo dirigía el periódico Jornada que era un semanario, el único órgano de prensa que estaba de su lado y que hacía campaña por él. Y yo era, bajo el nombre de gerente, el auténtico director de ese periódico, junto con Miguel Benavides, su dueño. Pero Miguel había formado el periódico para una presunta candidatura de su tío, el Mariscal Benavides, que no ligó. ¿Qué me enseñó primero, Bustamante? Esto es importante: dice Paco Igartua, en un libro autobiográfico, que encontrándose él en casa de un condiscípulo en La Colmena, en la cual se encontraba alojado Bustamante y Rivero, llegó Roberto McLean, líder de la facción parlamentaria de Prado en su primer gobierno, quien iba por don José Luis para llevarlo a Palacio, a pedido de Prado. Y cuando regresó don José Luis, el dueño de casa le pregunta que cómo le había ido. "Un horror. ¿Cómo puede un Presidente de la República pensar [ello]? Es dueño del poder y me dijo que desearía que yo fuera el candidato del gobierno en la próxima elección del año 45. Me ha hecho 20,000 ofertas y explicaciones de que tengo asegurada en esa forma la Presidencia de la República. Es decir, se dispone del poder. Un hombre como Prado, de quién soy embajador en Bolivia, y que me ha hecho venir especialmente para pedirme que sea su sucesor en el poder; pero impuesto por el gobierno, indirectamente, no directamente. Vengo repugnado".

\section{Una antigua forma de hacer política.}

Sí. Pero si Prado había sido puesto por Benavides y por eso éste se resintió cuando quiso regresar para ser candidato; y Prado se opuso. Bien, pero aquí no termina la historia, por muy embajador que fuera [Bustamante y Rivero], estaba ya dentro de la carrera presidencial, porque antes había sido embajador en Uruguay y luego pasado a Bolivia. Vino de Bolivia a pedido de Prado. Pasado el tiempo se convierte en el candidato ¿de quién? del Frente Democrático, que era la oposición a Prado desde el punto de vista democrático. Por supuesto, no se "tapó" al gobierno de Prado, porque Bustamante había sido su embajador. Pero él, que le había rechazado al Presidente Prado su ofrecimiento para ser candidato, en cambio aceptó la oferta de Benavides y Haya, en el Frente Democrático. Haya tenía antecedentes de ofrecer colocaciones a determinadas personas; como había sido el caso de Bustamante cuando Prado le ofrece ser candidato. Haya estaba esperando tranquilamente el tratado de paz del término de la Segunda Guerra Mundial, con lo cual el APRA iba a ser aceptado nuevamente como partido inscrito en el Perú donde estaba marginado y así tener la oportunidad para postular. Imaginó que Bustamante declinaría también esta oferta. Bustamante, en cambio, la acepta con condiciones: el "Memorándum de La Paz", donde se plantea lo que después el APRA no quiso reconocer: "Mi gobierno es un gobierno de transición; hoy no se vive democracia, mañana no se puede vivir directamente democracia; hay que prepararse para vivirla. Este gobierno va a ser un gobierno intermedio. Después vendrá la plenitud democrática". Bustamante acepta ser candidato pero no porque se lo ofrezcan Haya y Benavides, no, sino porque ellos, más la gente no afiliada a ningún partido, que era la más numerosa, ofreció tenerlo como presidente dentro de los límites del memorándum que había pasado desde La Paz.

\section{Eso era una ruptura, casi revolucionaria de la forma de hacer política.}

Así es.

\section{Y fue creando una transición hacia lo que en la segunda mitad del siglo $\mathrm{XX}$ se va configurando como esa democracia incipiente que aún estamos viviendo.}




\section{REVIEW}

OF GLOBAL

\section{MANAGEMENT}

FACULTAD DE

NEGOCIOS

UPC

Así es. Con otra condicionalidad. Él había rechazado el poder dadivoso, no había aceptado el ofrecimiento democrático incondicionalmente, había dicho "yo voy a hacer un gobierno intermedio porque no se puede pasar de un salto a una democracia desde una dictadura continuada". El trabajo de Benavides desde el año 33 hasta el 39 y el de Prado del 39 al 45, doce años continuados con la ley de emergencia no pueden darnos el sitio para un gobierno democrático automático. Eso tiene que ser la materia en que se prepare al país y se registre en condiciones de entrar a un gobierno democrático en el siguiente periodo con una democracia asentada; mientras tanto tiene que haber una colaboración permanente dentro de una unidad de mando. No hay precedente en la historia republicana en que un hombre, ofrecida la candidatura por el poder para que suceda en el poder, diga no y menos un hombre, ofrecida la candidatura por la oposición, pone condiciones para aceptar y condiciones en cuya virtud no va a ser el gobierno de ensueño que se predique en una campaña, sino en la responsabilidad de un gobierno que tiene que ir acomodando las instituciones a una realidad a la cual tendrá que irse plenamente en un segundo gobierno. Porque esa era la esencia del Memorándum de La Paz. A mí, eso me impresionó tremendamente.

\section{Es uno de los fundamentos de su admiración por Bustamante y Rivero.}

Es que también era uno de los fundamentos para un tránsito como siempre reclamó don José Luis. El cambio, después diría, no puede hacerse exabrupto, el cambio debe ser gradual, el ser humano cambia gradualmente.

\section{Lo más natural.}

Y esa fue su ley, por eso su personalidad me cautivó, como lo había sido la de León Barandiarán durante mi etapa de alumno o como había sido en la conducta del historiador, después profesor de Derecho Procesal, Manuel Sánchez Palacios. Yo he tenido, claro, a eso le agregamos a Víctor Andrés Belaúnde, yo he tenido siempre en mi vida, hombres rectores, cuyo ejemplo, silenciosamente, yo no conocía a Víctor Andrés Belaúnde, pero ahí está la carta...

\section{Manuscrita.}

... que escribió Víctor Andrés Belaúnde, seis días antes de morir mandada de las Naciones Unidas, cuando nadie avisaba que él estuviera mal, con el escritorio al costado de Doña Teresa, su mujer, y enviada después de fallecido Belaúnde. Yo la recibo después de muerto Belaúnde, traído por uno de sus hijos, porque el destinatario de la carta, no la habían despachado para él, no tenían mensajero para que la trajeran, yo había ganado la reelección el 66, y esa carta la escribió seis días antes de morir, pero no tenía con quien mandarla, la trajo su hijo después que él había muerto.

\section{Esos son los hombres que lo marcaron a usted: familia,} amigos, maestros, intelectuales. En el Perú se va haciendo cada vez menos frecuente ese reconocimiento a los otros porque ya no es usual hacerlo o porque hay menos personas que tengan esos valores.

Hay gente portante de valores. Lo que hemos olvidado es que los momentos de la historia son muy complejos. El pensamiento nuestro, alguna vez lo dijo Bolívar cuando analizó al Perú, era, sumiso en la dictadura, anárquico en la libertad. Dura opinión, perversa en la brevedad y en el acierto; un estigma imposible de modificar ... sumisos en la

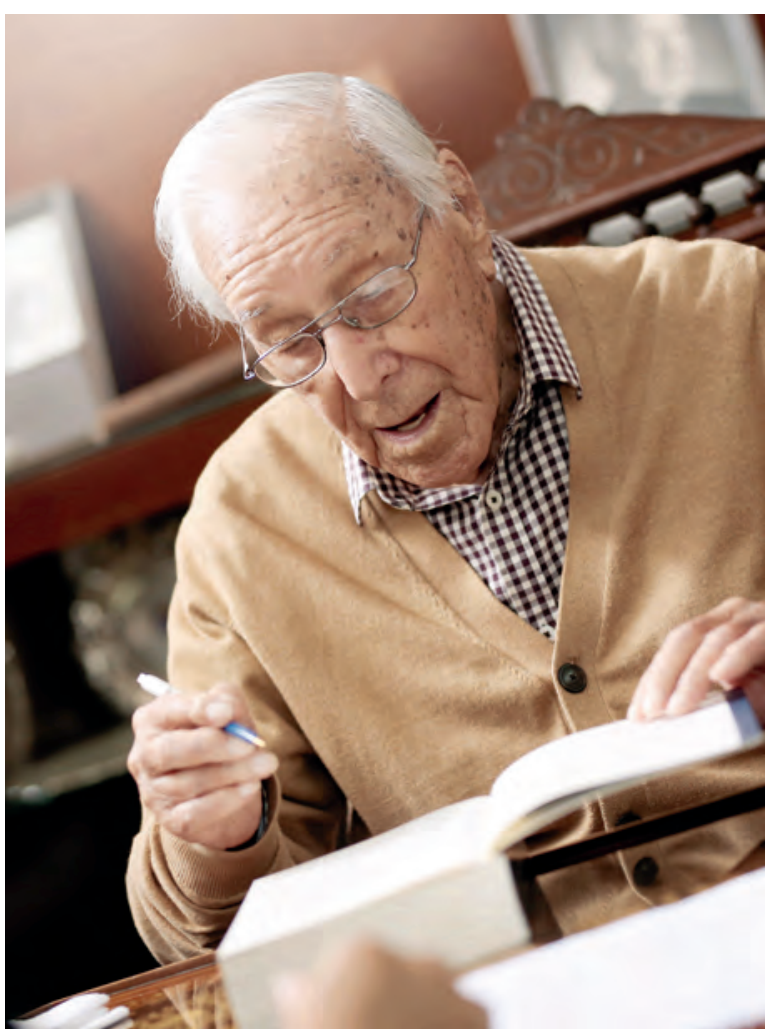


dictadura, nadie alega contra el dictador, todo el mundo se somete, rumia tranquilo, peleas, en pocas palabras, pero no enfrenta. La masa se somete al dictamen. Cuando tienen libertad como ahora, entra la anarquía. Este es un régimen de libertad, eso automáticamente es anarquía, no hay dos sectores que se junten, todos son enemigos.

\section{Nadie cede.}

Nadie transa; nadie cede; nadie negocia jurídicamente.

Cuando usted hace esa reflexión, pienso en las razones que lo llevan a elegir ideológicamente la Democracia Cristiana. ¿Por qué lo digo? Porque los demócratas cristianos son los que siempre han buscado el diálogo, recordemos a Adenauer y a Schuman ¿Vio usted en esa capacidad de diálogo, algo que lo llevó a su inicial pertenencia a la Democracia Cristiana y luego también a su alejamiento?

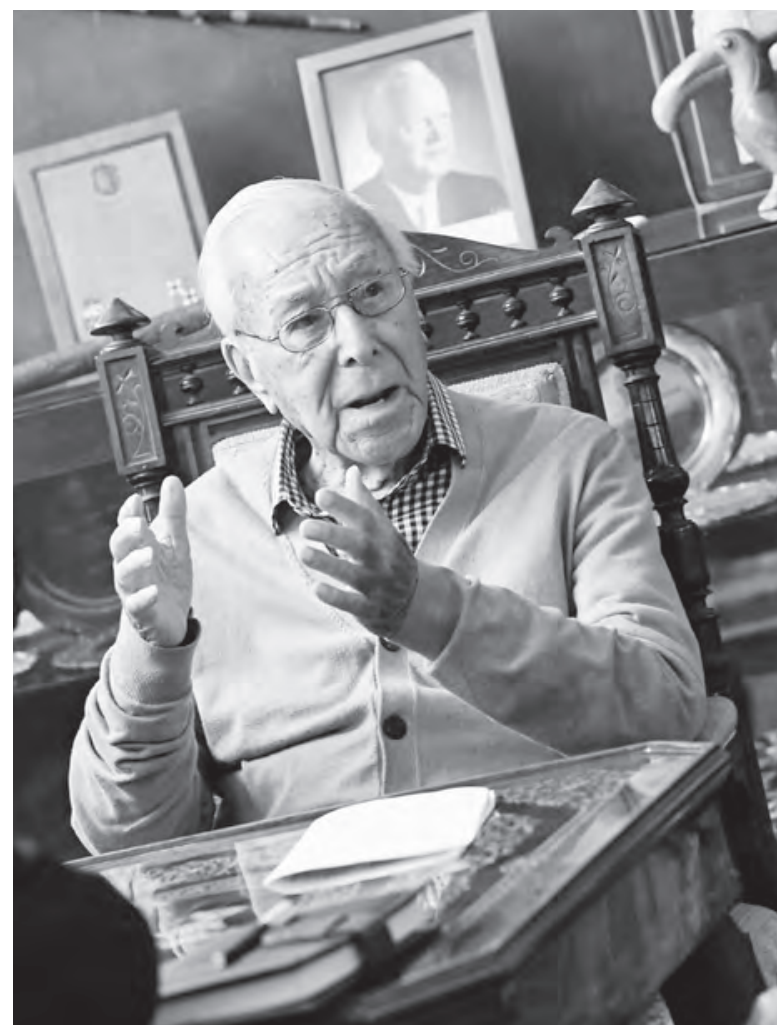

Lo que puedo decir de mí es que estaba en la línea de la Democracia Cristiana en el momento en que había militado en la Acción Católica; movimiento que había generado el Papa Pío XI, inspirado en la encíclica Rerum Novarum de 1891, en la que León XIII critica los excesos y fallas del pensamiento de Marx y del pensamiento liberal e invoca algo que después va a ser levantado en la carta de las Naciones Unidas. ¿Cómo podía sintetizarse en una palabra? Dignidad humana. El pivote de la democracia es la presencia del respeto a la dignidad humana, a su libertad, a su modo de ser, a su libertad de creer y de militar en su propia creencia. Todo lo que la carta recoge nace de ahí, porque la dignidad humana nace para el hombre por el acto de la creación, cuando Dios creó al hombre a su imagen y semejanza. Esa percepción de la Iglesia con respecto a la naturaleza del ser humano, creado a imagen y semejanza del Creador, es la que contiene para el creado un contenido de dignidad que es el pivote de su vida misma y la razón de su existencia.

La dignidad del hombre. Yo militaba en la Acción Católica pero, en un país como el Perú, donde por desgracia no había una clerecía innovadora como la que había en ese momento en Italia o en Alemania, después de la guerra y en toda Europa, se encerró más bien en una posición catequística en vez de impulsar el cambio social y económico, razón por la cual la trilogía de la Acción Católica--estudio, acción y piedad--, llevó más a un mundo catequístico que a un mundo cambiante. La gente se abrió en algunos países, comenzando por Chile y Venezuela y tomaron de la Acción Católica la acción que nunca se había practicado. Por ejemplo, en el caso de Chile, la Falange, que contiene el pensamiento social cristiano, ¿cómo nace? era la juventud del Partido Conservador. Y es de ahí que sale para formar un nuevo partido, que inicialmente se llamó Falange pero que después tomó el nombre de Partido Demócrata Cristiano. Igual ocurrió en Venezuela y en otros países. Aquí en el Perú no, la Iglesia todavía pretendía ser la que orientara el gobierno político pero discreta. La tolerancia era temor, no se ponía pasión en el cambio, se temía ser confundido con las tendencias marxistas o tener cualquier tipo de alianza o diálogo con ellos; eran los excluidos.

En política no hay excluidos; es un diálogo inter pares cualquiera sea su convicción, que busca una línea de entendimiento que sume el esfuerzo de dos o más frente a la soledad. La democracia es fundamentalmente entendimiento y el entendimiento entre dos distintos 
REVIEW

OF GLOBAL

MANAGEMENT

FACULTAD DE

NEGOCIOS

UPC

reclama la tolerancia; alguien tiene que ceder y lo ideal es que los dos cedan algo. Es una invitación a repensar la política.

La democracia cristiana triunfó, a través de Helmut Kohl. Han estado a la cabeza de Alemania por 30 años. La Alemania derrotada ha pasado a ser la cabeza y si China no fuera tan grande, la cabeza del Oriente sería Japón, que lo fue inicialmente, antes de que el comunismo ganara a la república.

Con esa mirada que usted hace de la democracia, estando el Perú republicano próximo a cumplir 200 años, somos todavía un país joven y en búsqueda de nuestros equilibrios.

Somos un país joven, pero simultáneamente de una gran diversidad que no intenta conscientemente una unidad. Desde el punto de vista social, el aborigen no es tratado como un igual. A lo largo de toda la vida republicana las separaciones de clases sociales han sido muy marcadas. No nos hemos dado cuenta del cambio fundamental en cuya virtud otros países han podido derivar. La última gran conmoción y la primera, fue la Revolución Francesa, cuyo lema era igualdad, libertad y fraternidad. Inicialmente, toda la lucha de la revolución fue la lucha por la libertad, a diferencia del sistema marxista, en donde no hay libertad sino sometimiento totalitario. Todos pelearon por la libertad a su modo, pero llegó el momento en que la democracia probó que el voto de la mayoría es el que gobierna. Y ahí vino entonces la segunda fase, ya no por la libertad sino por la igualdad. La consecuencia de la Revolución Francesa fue durante el siglo XIX la lucha por la libertad pero, actualmente y desde hace muchas décadas, por la igualdad. Muchos países la han conseguido y son los más prósperos.

\section{Es un escenario difícil para el Perú.}

Sumamente, por la complejidad de su composición étnica y cultural.

\section{En algún momento dice usted que somos una sociedad precipitada en algunos casos.}

El desequilibrio poblacional y potencial es tan grande que el porcentaje del dinero se concentra en Lima por la contribución, pero también por el gasto. El resto del país tiene un ritmo muy distinto y muy distante. Actualmente hemos fracasado, además, aunque estamos enmendando, en la regionalización, impuesta por un decreto ley que hizo de cada departamento una región. Por ello, la regionalización no ha podido prosperar, recién se está enmendando, pero ya sin poder remodelar la composición de regiones auténticas, con recursos que puedan enfrentar los problemas, sino simplemente con la misma configuración de los viejos departamentos, cual modelo francés.

\section{Y una regionalización en el Perú tiene que ser algo transversal. Es prácticamente lo que la naturaleza manda.}

Así es. Somos no competitivos en el sentido longitudinal, pero transversalmente somos complementarios. Y en vez de formar regiones de la costa hacia la selva, formamos departamentos de costa, de sierra y de selva. Es decir, consagramos lo diferente. Tendrán que rehacerse las regiones. Conforme éstas se desarrollen; eso vendrá

Y ahí el agua es fundamental porque para la configuración que tenemos, no hay población si no hay agua, y no hay agua si es que no se tiene agua en las cuencas superiores.

Lo estamos viendo, sobre todo, el caso más próximo es la abundancia en Huancavelica con la sed en Ica.

Pero lo desarrollado por el Gobernador Regional de Ica ha sido sumamente favorable.

Claro que sí.

\section{Ha alentado el diálogo.}

Si. Pero por más que adelante, no está consagrada todavía la entrega del agua necesaria para aumentar las hectáreas de riego en el departamento de Ica.

Y en esa mirada de país ¿qué líneas matrices debe desarrollar el empresariado, teniendo en cuenta los roles que ha cumplido y los roles que debe cumplir?

Mucho han hecho los CADE2 . En el sentido de reunir al mundo empresarial y constatar sus limitaciones y sus opciones; por lo menos, se ha hecho conciencia. Y ha 
estado en manos de gente prudente para ampliar la filosofía del momento. Una cosa, eso sí, es lo que uno dice y reconoce pero no practica. Siempre se piensa que el otro debe ser el que practique. Nadie se mira al espejo.

Hablar de empresa es hablar de generación de riqueza. La generación de riqueza consiste, finalmente, en la asignación eficiente de recursos escasos que permita mejorar el bienestar material de la población. Entonces, ese necesario impulso que el empresariado le ofrece al país es el gran motor de la economía. ¿Los empresarios tienen demasiada responsabilidad?

Sí. Pero por ser "contreras" el empresariado se dejó sacar ventaja por las fuerzas sindicales que han obtenido mucha concesión, deformando el orden de entonces. Actualmente, en realidad, la pequeña empresa sufre las consecuencias de esa deformación que ha permitido una serie de leyes que da al trabajador una posición ventajosa que limita las posibilidades de hacer empresa. Dicen que los "renglones" no salariales son los que impiden este desarrollo, pero al final de cuentas es que al negar todo han terminado perdiendo las peticiones que en las épocas de anarquía, originaron los sectores laborales. Si vemos las fechas en las que se han obtenido ventajas, son fechas difíciles y de lucha. Hoy día, está muy tranquilo el sindicalismo, pero es que tiene que hacer la digestión.

\section{Empresa, sindicalismo y creo que para completar el} trípode, el Estado.

El Estado siempre ha sido neutral, como réferi. Le ha negado visiblemente al sector laboral muchas cosas, pero al final, frente al golpe de las huelgas y la presión de los sindicatos en las épocas electorales con capacidad decisoria muchas veces ha tenido que ceder. Ahí es cuando han tenido lugar las ofertas de ventajas, nada menos que con la venia de algunos sectores empresariales. Estas llamadas reformas están mal concebidas y necesitan ser reajustadas. Es muy fácil decir que la deformación está dada por las asignaciones no laborales, pero una vez que hicieron el nudo es muy difícil desatarlo. Hemos visto que lo primero que hizo el ministro de trabajo [Sánchez Reyes] es renunciar.

Hasta ahora hemos abordado tres grandes temas: el primero, la reflexión sobre las personas que marcaron su vida como elementos inspiradores; el segundo, el modo con el cual usted ha concebido también la democracia y las vicisitudes que ha ido teniendo y cómo este pensamiento del doctor Bustamante y Rivero en cierta forma marca un punto de inflexión a lo que significa no dádivas sino, creo entenderlo así, institucionalidad; y el tercero, la reflexión que usted ofrece sobre el rol del empresario.

Un factor adverso es el tiempo largo que demoró el APRA para madurar. Si el APRA hubiera madurado rápido otra habría sido la historia del Perú. Y es que el APRA nunca transó. Levantó sus propias banderas, el SEASAP: "solo el APRA salvará al Perú".

\section{Nació radical.}

Y una radicalización dada en la palabra, porque cuando le tocó ser gobierno, sin control, hay discursos impresionantes con los cuales en seis meses se borró la ley que da la instrucción gratuita; en seis meses se modificó la ley que aumenta a los profesores; en seis meses... pero lo que no había era cartera. ¿Dónde estaba la plata? Hubo que fabricarla y vinieron las etapas de las inflaciones. Fabricar moneda es muy fácil si se está en el poder.

Me trae a colación, una entrevista de César Hildebrandt a Pedro Beltrán, quien hizo alusión al modo en el cual la emisión de dinero inorgánico era la causa directa de la inflación y que según Beltrán el tema pasaba por una prioridad, el costo de vida. Y creo que, efectivamente, eso también ha ido cambiando en el Perú; o sea, ese modo en el cual se emitía moneda entusiastamente ha dado paso a un equilibrio macroeconómico, de mucha responsabilidad y que es el sustento que hace que el Perú pueda ser visto como una economía más estable.

Nos faltan financistas y nos faltan economistas. Recién las nuevas generaciones estudian estas disciplinas en la universidad en adición a las tradicionales profesiones. Recién tenemos realmente una legión de economistas, importante para los cambios imprescindibles. jBasta de abogados! Faltan médicos, también; pero yo creo que ingenieros tenemos, aunque tradicionalmente han sido ingenieros, médicos y abogados las tres profesiones liberales. Economistas, solamente como Pedro Beltrán venido del extranjero después de haber hecho cursos en Francia. 


\section{REVIEW}

\section{OF GLOBAL}

\section{MANAGEMENT}

FACULTAD DE

NEGOCIOS

UPC

Haber profesionalizado al Estado es un logro enorme.

Así es. Ya no se puede improvisar la función y tarea de los ministros. Tienen que ser expertos en su materia. No hay ministros anónimos.

Porque antes, eso de una u otra manera lo podía hacer el gabinete mismo del ministro; el ministro era la figura política y en teoría había un sector técnico.

No. Nos faltó lo que tienen normalmente los estados descentralizados. Una organización administrativa hecha a base de carrera profesional. En Francia, no se puede entrar a partir de cierta categoría administrativa sino con estudios

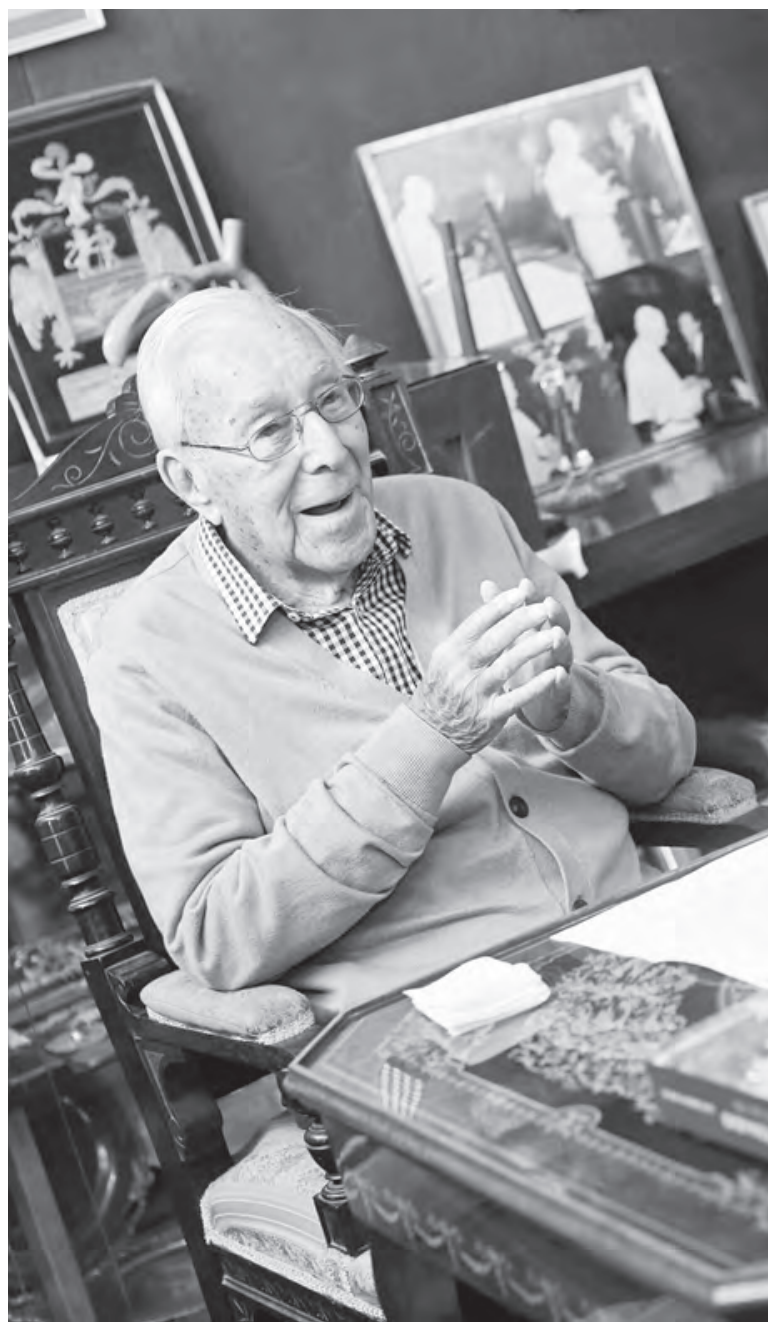

previos. Y eso ocurre en todos los países. Aquí en cambio buscábamos a gente con apellido sonoro a los efectos de ocupar ministerios, pero no siempre acompañados de un conocimiento suficiente de la realidad nacional. El Perú ha tenido castas en vez de clases.

\section{Creo que tiene el mismo carácter de lo que Bolívar opinó sobre el Perú.}

Sí señor

\section{¿Y qué ocurre cuando un país sustituye las castas y crea clases?}

La estadística, la educación, la profesionalización de la gente; esto representa el termómetro.

\section{Meritocracia.}

Lógico. Productividad.

\section{Se va por buen camino entonces.}

Sí. Vamos tomando conciencia de que sin "tecnicismo", sin preparación del trabajador en su rendimiento y sin el aumento de la productividad de cada ser, no podemos avanzar. Chile, mientras hemos dudado de lo que nos tocaba hacer, nos ha sacado más de 20 años de ventaja. No es por emular pero es la realidad. Colombia también nos ha sacado buena ventaja. Venezuela no, mono-productivo. Y ahí está arruinándose. Y Ecuador

también, aunque en menor forma; y Bolivia también, país distinto.

Y ese pensamiento, que en algún momento tuvo el APRA, sobre pensar una Hispanoamérica, siguiendo el pensamiento de Bolívar ¿sigue siendo vigente una mirada continental?

Sí. Pero estamos viendo la Unión Europea; por ser cultos estos países y organizados es que eligieron un país como Alemania. Inglaterra está todavía peleando las condiciones en que se libera.

Parece que no ha sido la mejor decisión para los ingleses retirarse de la UE.

Lógico. Pero parece que el pueblo tampoco estaba 
dispuesto a soportar lo que considera una desventaja, porque tuvieron un plebiscito previo para separarse.

\section{Qué difícil aspirar a una integración perdiendo identidades.}

Así es. Pero el mundo sigue dando vueltas; no siempre para bien pero hay países que se levantan enseguida por su disciplina, como Japón, por ejemplo.

\section{Me permití, mientras lo esperaba, ver algunas de sus fotografías. Advertí una del Emperador del Japón.}

Sí, cuando era todavía el príncipe. Ya dejó de ser el emperador.

\section{Cuenta en su libro que usted recibió al Príncipe y a su esposa en el Palacio Municipal.}

Sí, claro. Igual que hemos recibido a personalidades de primer nivel durante esos seis años. Los astronautas hicieron gran impacto. Y sobre todo Christiaan Barnard, el famoso médico del primer cambio de corazón. Me permití [la licencia de] preguntarle en la presentación que tuvo en la municipalidad, si un hombre casado cambia el corazón, que es el que contiene los sentimientos, realmente se encuentra con el corazón de otro, que no coincide para efectos de la sintonía con una persona, como la señora que sobrevive con él.

En una parte de su libro, me llamó la atención su reflexión sociológica sobre El Callao: "donde nadie es más". Creo que ello también lo define a usted. ¿Esa es su percepción de vida?

Sí. Todavía voy [a El Callao]. Por razón de la construcción tradicional en El Callao, que es muy antigua, el interior de las casas es muy limitado. Por eso se invita al barrio, no se invita a la casa y las grandes conversaciones se hacen en la esquina. Ello ocurre, tanto con los importantes, como con los estibadores. Es una tradición en El Callao, en los barrios y en las proximidades del mar.

Igual que en las provincias, las construcciones en El Callao dan la espalda al mar, con excepción de La Punta y Chucuito. Al mar se botaban los desperdicios; las acequias corrían hasta el mar. Ni tocarlo. Ni mirarlo. Que la Mar

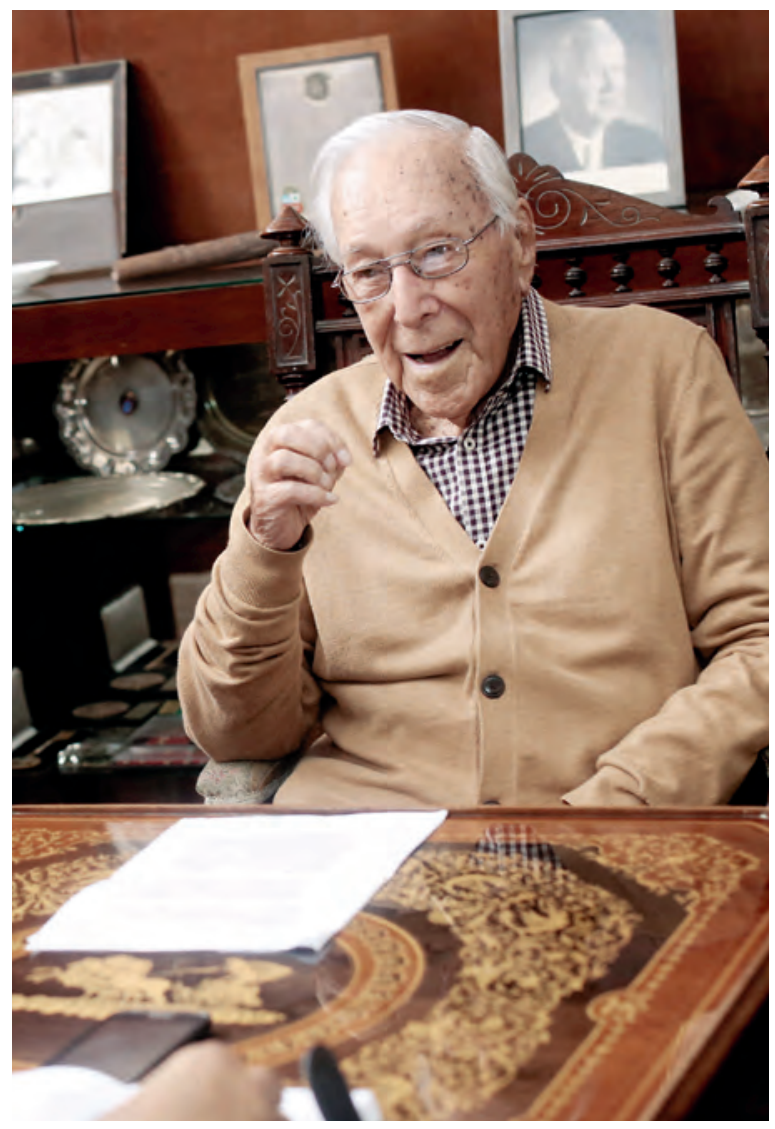

Brava se lo lleve todo.

Como alcalde, usted concibe el zanjón, amplía la Costa Verde e invita al limeño a recorrer la proximidad de su mar, lo que antiguamente no se hacía.

En realidad, la gran ventaja para el mar, la generó la Vía Expresa. Las miles de toneladas que hubo que excavar fueron a parar como respaldo a los grandes bloques de piedra que sirvieron de molones, penetrando al mar y orientando su corriente. Agua Dulce no era como es hoy. Y las playitas que existen, casi todas tienen las piedras de las moles que salieron de la Vía Expresa. Para ello consultamos más de una vez a ingenieros de mar, para que nos indicasen, entre otras cosas, la dirección de las corrientes, y poder dar instrucciones a los camiones de acarreo. Eso modificó sustancialmente el paisaje en Lima. Actualmente, la playa que corre desde Chorrillos hasta La Punta nació de esos molones. Y La Punta, por ello, se ha protegido con una gran defensa. 


\section{OF GLOBAL}

\section{MANAGEMENT}

FACULTAD DE

NEGOCIOS

UPC

Ubicación privilegiada, la de Lima, frente a las demás capitales de América.

Si. En general, gracias a ello, Lima es el punto de contacto con el Oriente; más de lo que suponemos.

\section{Cuando usted llega a la alcaldía ¿sintió el peso de lo que significaba una institución secular como ella?}

La idea en sí me persiguió durante toda la campaña. Sólo la confesión que personalmente me hizo Belaúnde --"yo no creo que usted pueda ganar porque son dos fuerzas que suman más que nuestros votos. Yo gané cuando Haya fue candidato y también Odría; les gané a los dos, pero no a los dos sumados sino a cada uno de ellos. Lo llamo para que me acompañe porque tiene usted condiciones para hacer una campaña; lo único que le pido es que me dé más votos que los que obtuve cuando me eligieron, porque no he perdido. Y a tres meses de mi elección, no puedo admitir una pérdida en la votación de respaldo. Eso para mí es más grave; por eso el 15 de diciembre, no se preocupe, va a perder, pero el 16 de diciembre está jurando como ministro". Esto que para él era una especie de

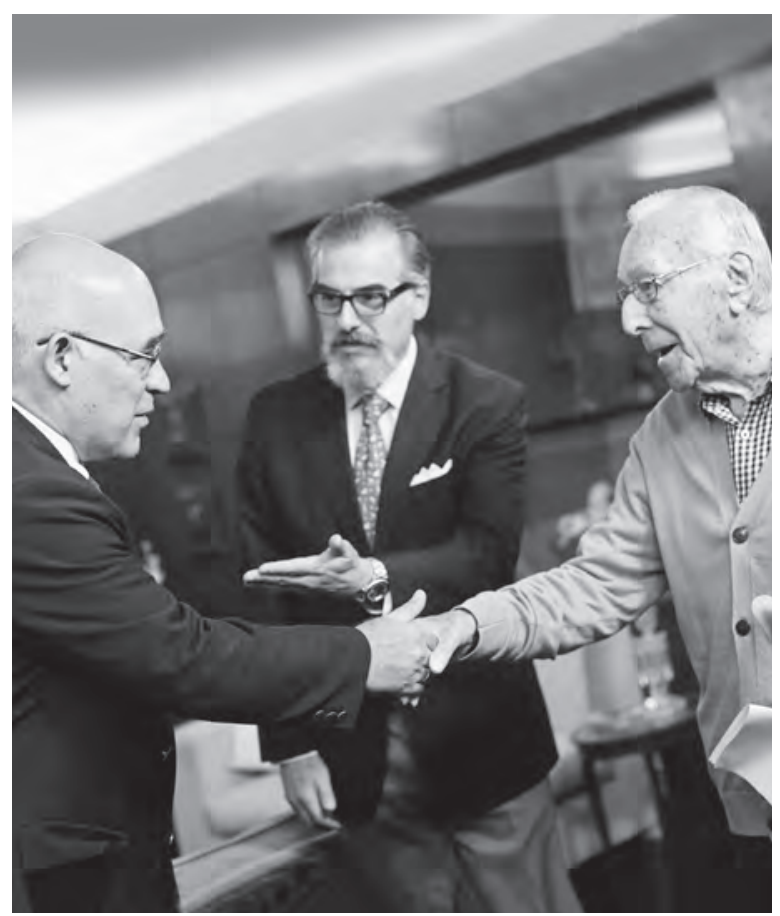

compensación, sinceramente me dejó mareado: vas a regresar a tu casa con el cargo de ministro como un triunfo de consuelo.

\section{Alcaldía y ministerio.}

Sí. Pierdes en la alcaldía porque no tienes nada que hacer; vas a perder, pero yo te voy a reponer como ministro iqué tal triunfo pírrico!

\section{Victoria pírrica, que no lo fue.}

Pero me amargó la campaña. Algo así como el jinete, corriendo los últimos 200 metros, fustigando al caballo... ¡Y yo era el caballo!

Me esmeré entonces en la campaña, pensando que iba a perder. La vergüenza de [Belaúnde] quien me daba como compensación por la derrota el ministerio. jPero no hubo ministerio!

\section{Lo acicateó mucho.}

A Dios gracias no me duró.

\section{Porque podía ser paralizador.}

Y todavía combatiendo contra una mujer a quien, por caballerosidad, no podía llevar a un duelo verbal. Tenía que respetarla. Quienes sabían eso eran sus estados mayores: todos aquellos que Odría y el APRA habían guardado para hacer su gabinete. Ambos partidos llevaron su mejor gente como concejales y a la señora Delgado como candidata. Menuda cosa.

\section{¡Qué coyuntura! La supo capear bien.}

Con las justas, porque mucho más saqué de distancia y diferencia cuando el competidor fue el ingeniero Grieve; hombre muy capaz.

\section{Usted lo respetaba mucho como profesional.}

Tenía fama y valía. Pero lo que ocurre es que él venía con la teoría de los mercados y yo con la realidad de los mercados. De manera que la gente que me veía a mí oía lo que le pasaba cada día y la gente que lo oía a él no entendía bien lo que quería decir. 


\section{Nota Final del Entrevistador:}

Cuando lleva el Perú transitando apenas dos décadas del nuevo siglo y con el entusiasmo por el advenimiento de los fastos que deben acompañar a la celebración del Bicentenario de la Independencia en 2021, aún subsisten muy valiosas experiencias vitales con honda repercusión en la política nacional. Una de ellas es la encarnada por don Luis Bedoya Reyes, orador de fuste, político concertador y duro rival de sus adversarios, quien representa una estirpe casi extinta de políticos en el Perú. Antiguo guadalupano, de una época en la que la educación pública secundaria destacaba con nitidez, y abogado formado en las aulas de San Marcos, Bedoya hizo una brillante carrera política: dos veces alcalde de Lima, cuando la ciudad daba sus primeros pasos en cuanto a su expansión urbana en la década de 1960; ministro de Estado, y luego como Constituyente, son los hitos de ese feraz tránsito por la azarosa política peruana. Por todo ello y a la luz del valioso testimonio de vida que con generosidad nos ha brindado, la UPC Review of Global Management le extiende su más profundo agradecimiento al decano de los políticos peruanos. Estamos seguros que sus opiniones sobre la evolución de la política en el Perú, y los escarceos, concertaciones e ideas que la acompañan, o las que ofrece sobre su propia trayectoria vital, echarán luces valiosas al conocimiento del ajetreado siglo XX

peruano; y no dudamos que sabrán ser aprovechados, tanto por nuestra fiel lectoría, como por toda persona comprometida con el futuro del país.

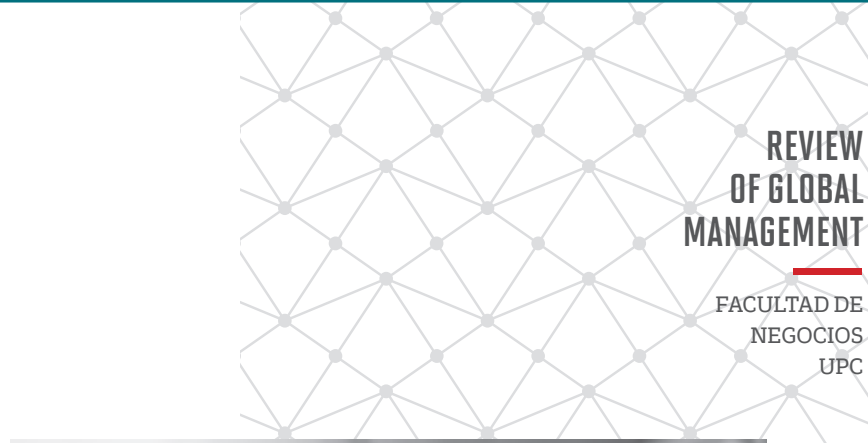

\section{Referencias:}

Bedoya, L. (2018). Joven centenario. Realidades de una vida. Lima: Fondo editorial del Congreso del Perú 